\title{
THE POTENTIAL OF STRAVA DATA TO CONTRIBUTE IN NON-MOTORISED TRANSPORT (NMT) PLANNING IN JOHANNESBURG
}

\author{
M. K. Selalaa, *, W. Musakwa ${ }^{\mathrm{b}}$ \\ ${ }^{a}$ Faculty of Engineering and Built Environment. Dept. Quality and Operations Management, University of Johannesburg, \\ Johannesburg-kadibetsos7@gmail.com \\ ${ }^{\mathrm{b}}$ Dept. Town and Regional Planning, University of Johannesburg, Johannebsurg- (wmusakwa@uj.ac.za)
}

KEY WORDS: Non-Motorised Transport, cycling, crowd-sourced data, Strava, Origin, Destinations

\begin{abstract}
:
Transportation is one of the most fundamental challenges of urban development in the modern world. Cities are currently moving towards sustainable transportation, which includes non-motorised transportation (NMT). The city of Johannesburg has a goal of becoming a smart city, with sustainable development and smart mobility. Encouraging the use of non-motorised transportation and public transport has the potential of reducing the use of private motorised transport and therefor its negative consequences within the city of Johannesburg. There is limited research on cycling and how cyclists interact with cycling infrastructure within the city. The lack of such knowledge hinders proper planning for NMT. This research studies the ability of geolocation based services to provide such information which can be useful in planning for NMT. Strava Metro application is the example of such geolocation based services. The potential of this app to influence planning is investigated. According to the information acquired by Strava Metro, there are more cyclists in suburbs at the centre of Johannesburg and towards the north and to the east, and in Kibler Park at the south western part of the city. There are indications that the numbers of cycling activities recorded by Strava Metro are affected by the availability of gated communities, income levels, crime levels and the provision of infrastructure.
\end{abstract}

\section{INTRODUCTION AND LITERATURE REVIEW}

Transportation is one of the most fundamental challenges in urban development in the modern world (Jou, 2011). Accommodating motorcars has been an important theme of modern planning in many parts of the world (Todes, 2009; Behrens, 2004). Traffic congestion presents significant environmental, social and economic costs (Navarro et al., 2013; Neutens et al., 2012). The consequences include high resource consumption, externalities such as emitting greenhouse gases (Kenworthy, 2003).

High levels of dependence on the motor car, and the low densities developments make access difficult for those without this form of transport (Newman \& Kenworthy, 1996). The emphases on planning for mobility in cities abandon the significance of non-motorised forms of transport in developing countries (Behrens, 2005). Little attention is paid to the needs of NMT users for road space, crossings, and other amenities, resulting in high levels of accidents (Todes, 2009).

To solve the traffic problem, several solutions have been suggested. One was to reduce the trips people have to take, meaning that people have to travel less (Waterson et al., 2003). This could be possible through mixed land use neighbourhood (Marquet \& Miralles-Guash, 2015). The affordability, safety and convenience of public transport (Filippi et al., 2013), and to encourage non-motorised transport (Visser et al., 2003). Non-motorised transport is any form of transport that does not rely on battery and/or fuel combustion driven mechanisms (Yazid et al., 2011). This is a fully human powered mode of transport. Examples include walking, cycling, per-ambulating, using donkey, horse or human-drawn carts/trolleys and rickshaws (Mammon et al, 2008).

Cities should strategically improve the transit and nonmotorised mode alternatives to avoid traffic congestion (Frank et al., 2010). Within the area of public policy is where intervention can occur, through the increase in densities and concentration, through mixed use development, housing location, the design of buildings, space and route layouts, PT oriented development and transport development areas, car-free development, and through establishing size thresholds for the availability of services and facilities (Banister \& Hickman, 2006). In recent years, promotion of NMT has moved up multiple policy agendas, including in relation to health, transport and climate change (Blanco et al., 2009). Favourable urban form is a critical factor in creating sustainable and energy efficient and greenhouse minimising urban transport systems (Blanco et al., 2009).

Despite the interest and the availability of additional funding for NMT, there are limits to how and where it can be applied (Kenworthy, 2003). Decisions about where and how to invest in NMT infrastructure are hindered by lack of empirical studies on cycling activities (Ali Hussein, 2015). Prioritising investments into improving bicycle facilities is critical for metropolitan areas (Handy \& McCann, 2010). It is quite clear that cleaner air and safer streets come at a price, and only with well thought out long-term policies (Mohan, 2002). It is critical for metropolitan planning organizations and cities to effectively and accurately assess demand, connectivity, safety, and community goals (Handy \& McCann, 2010).

Most public transport trips involve an element of the use of NMT at the beginning or end of each trip (Mohan, 
2002). It is possible to redesign the existing roads to provide a safer and more convenient environment for NMT modes (Mohan, 2002). Most cities promote NMT by demarcating bicycle lanes, cycle tracks sideways roads, or bicycle paths that are not in conjunction with current roads (Broach et al., 2012). City planning experience in Beijing in China to Portland and in the USA suggests designing streets so that walking, cycling and the use of rickshaws become safer and more pleasant (Lamondia \& Moore, 2014).

\subsection{NMT in South Africa}

Political and technical decision-makers in South Africa are often not interested in public transport and NMT because of their attachment to cars (Todes, 2009). This is because cycling in South Africa is a relatively dangerous activity as cyclists are not very visible and are generally not considered equals by motorists in terms of access to road space (Todes, 2009). Cycling in South Africa is seen as a means of recreation or a mode of transport for the poor (Gwala, 2007). On many roads, there are no places for pedestrians and cyclists (Mohan, 2002). Current analysis on transportation patterns show that the focus mainly remains on prioritising the private vehicle with large investment in 'roadways for movement', as opposed to promoting PT and NMT (Dewar \& Todeschini, 2004). In the city of Cape Town, a public bicycle system has been introduced (Struwig \& Anderson, 2013). In theory, this was supposed to encourage cycling within the city since people did not have to buy their own bicycle (Jennings, 2014). Provision of infrastructure for NMT is an interesting and credible solution that needs to be seriously considered in South Africa (Mbara \& Celliers, 2013).

According to the Gauteng Household Travel survey (2003) cycling, accounts for $0.2 \%$ of trips in Johannesburg. Average travel time spent cycling to work is 42 minutes and to education is 16 minutes. The majority (approximately 90\%) of the walkers and cyclists are striders; however, about $10 \%$ of people are regarded as stranded, some walk or cycle for longer than 30 minutes because they cannot afford motorised transport (Navarro, 2013). Most cycling destinations are/were within a radius of $10 \mathrm{~km}$. As many trips in Johannesburg are longer, NMT routes also need to help people reach the PT networks (City of Johannesburg, 2013).

The City of Johannesburg aims to improve its NMT. Hence, one of the objectives of the Johannesburg Road Agency is to 'built, maintain, and manage PT and NMT infrastructure to support walking, cycling and the use of PT' (Johannesburg Roads Agency, 2000) and the adoption of the street alive programme as part of its safety and liveable city delivery program (Visser et al., 2003). The City's roads have traditionally been designed to cater more for motorists than they do for other road users (Visser et al., 2003). This program seeks to reverse this by prioritising the reallocation of road space to accommodate all users and by promoting road safety (Gwala, 2007).

There have been few surveys that have looked beyond motorised, peak-period and commuter travel, and these provide inadequate insight into the importance NMT in South African cities (Behrens, 2005). As a result, there is little information on the patterns, needs and trends of NMT users, particularly cyclists. This could be because data collection using conventional methods such as surveys is often costly, cumbersome, time consuming, out-dated and unreliable.

Perhaps using geolocation based services is a solution as it has been demonstrated elsewhere. As an example, the city of Salem used Strava to analyse the cycling infrastructure and cycling activities within the city (Strava, 2014). The results acquired were reliable (MacMichael, 2014), this motivate the study to follow such a technique to analyse the non-motorised activities within the city of Johannesburg. There are many other geolocation based services that people use to track their cycling activities and those that are known are: the 'Runtastic Road Bike GPS App', 'Map my Ride GPS Cycling Riding', 'The Sport Tracker', 'Eco Bicycle', most of this apps are available as mobile apps.

Strava Metro is a data service providing "ground truth" on where people ride and run. Millions of GPS tracked activities are uploaded to Strava Metro every week from around the globe (Strava, 2014). In denser metro areas, nearly half of these are commutes (Strava, 2014). These activities create billions of data points that, when aggregated, enable deep analysis and understanding of real world cycling and pedestrian route preferences (Strava, 2014). Strava Metro's mission is to produce state of the art spatial data products and services to make cycling, running and walking in cities better (MacMichael, 2014).

Using Strava Metro enables informed and effective decisions when planning, maintaining, and upgrading cycling and pedestrian corridors (MacMichael, 2014). The previous years have experienced a remarkable success in the use of mobile devices (Muhammed et al., 2011). This has placed governments in most countries under pressure to improve telecommunication technologies (Freire \& Paincho, 2014).

There is limited research on cycling and how cyclists interact with cycling infrastructure within the city of Johannesburg (Behrens, 2005). The lack of information hinders proper planning for how and where to invest in NMT infrastructure in the City. For example observations in the recently constructed cycling lanes in the Central Business District (CBD) are hardly used for cycling activity. Accordingly, this study proposes the use of geolocation based serves "Strava" as a way of acquiring information that can help understand the needs and the trends of NMT user and ultimately plan for NMT infrastructure. Consequently, this study aims to determine the usefulness of geo-location-based services in providing cycling trends and patterns in Johannesburg. Lastly how information obtained from Strava can be used to plan for NMT in Johannesburg is also investigated.

\subsection{Study area}

The City of Johannesburg metropolitan municipality area in South Africa was chosen as a study area. It was chosen because the city has an NMT policy and is developing NMT infrastructure. Yet little is known about the cycling patterns and trend in the city. Johannesburg is located within the Gauteng and together with City of Tshwane and 
Ekurhuleni is referred to the Gauteng City Region (Figure 1).

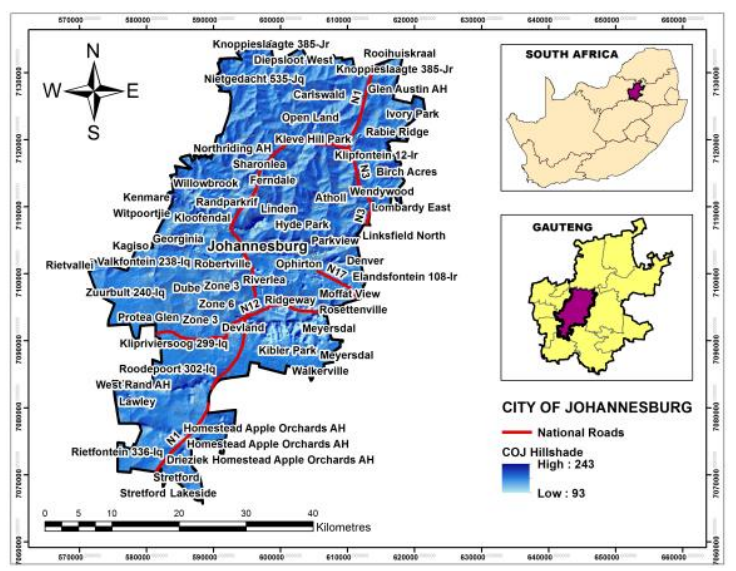

Figure 1: The City of Johannesburg map

Johannesburg consists of approximately 4.4 million people, accounting for about $36 \%$ of the Gauteng population and $8 \%$ of the national population (Todes, 2012). Johannesburg is the economic and financial hub of South Africa. Its economy and contribution to the national economy, has grown substantially and performed well on all major indicators when compared to other Metros. It contributes about $17 \%$ of the national GDP and approximately $47 \%$ of Gauteng's economy. Johannesburg ranked 47 out of 50 top cities in the world as a worldwide centre of commerce (the only city in Africa) (Angel et al., 2005). However, massive challenges in terms of urban poverty, inequality, unemployment, food insecurity, social exclusion and underdevelopment still remain.

The city consists of seven regions which are Regions A (Diepsloot, Kya Sand); B (Randburg, Rosebank, Melville, Northcliff, Parktown); C (Roodepoort, Constantia Kloof, Northgate); D (Soweto, Dobsonville); E (Alexandra, Sandton); F (Inner City); and G (Orange Farm, Lenasia). The municipal city's land area is approximately $1,645 \mathrm{~km}^{2}$ with a moderate density of approximately $2,364 \mathrm{~km}^{2}$ (municipal demarcation board, 2013). The population density is unevenly distributed throughout the municipal area. At a regional level, Region D is the most densely populated with $24.4 \%$ followed by Regions $\mathrm{G}(16.7 \%)$, F (13.4\%), A (12.6\%), E (11.8\%), C (11.6\%) and B (9.4\%) respectively.

Johannesburg is a sprawling city with a twofold transport system. It consists of a car-based system in the most developed areas, where automobile use is almost compulsory. In most neighbourhoods, particularly poorer and deprived neighbourhoods transport is either by way of commuter trains, minibus taxis and buses. Commuters and shoppers walk long distances to access facilities (Beavon, 2002). Johannesburg is a highly structured, fabricated and interlocked poly and multi-centric urban mosaic. On the one hand, it stands for "the luxury city and city of control" as reflected by Sandton, for example.

The walled and gated communities in the northern suburbs, for example, Sandton and Midrand, reflect the "gentrified city and the city of advanced services". The middle class South African areas such as Triumph (Sophia town) lend themselves to the "suburban city and city of direct production". The largely previously segregated townships for Africans and Coloureds which are leftovers of apartheid highlight the "tenement city and the city of unskilled work". Finally the "abandoned city and the city of the informal city" are depicted by the informal settlements which are generally located on the edges of townships or in any vacant spaces such as reflected by the inner areas, for example, Hilbrow. While the foregoing description does not do justice to a complex urban environment, it certainly provides a basis to frame the analysis (Beavon, 2002).

\section{METHODOLOGY}

\subsection{Research design}

The research is exploratory, and therefore utilises the Exploratory Spatial Data Analysis (ESDA). ESDA is a collection of techniques to describe and visualise spatial distributions, identify atypical locations or spatial outliers, discover patterns of spatial association, clusters or hot spots, and suggest spatial regimes or other forms of spatial heterogeneity (Anselin, 2012). Accordingly data form Strava Metro for the City of Johannesburg was collected and ESDA applied to reveal the cycling patterns, trends and distribution in Johannesburg for the year 2014. Strava data was chosen because it has been proven to be a useful source of data for cities such as Portland Oregon and Brisbane (Strava, 2015). Moreover to the best knowledge of the authors there are no complete datasets in Johannesburg that describe the spatial pattern and cycling patterns in the City.

\subsection{Data description and preparation}

Data from Strava Metro was obtained from Strava from Johannesburg. Strava Metro utilises data from Strava, which is a GPS enabled smartphone application that tracks bicycle rides and uploads the data to an online community of other users. Strava let's athletes all over the world experience social fitness sharing, comparing and competing with each other's personal fitness data via mobile and online apps (Smith, 2014). The GPS in mobile devices store points, which are then stored as Big Data on Strava Metro. Strava Metro therefore packages this data in GIS format to enable cities to better understand cycling patterns. Consequently this data was acquired and analysed in a GIS to reveal the cycling patterns, trends and distribution in Johannesburg for 2014.

Strava Metro has three licences, namely, (1) Streets, (2) Nodes and (3) Origins and destination licences. At present we were unable to acquire the streets or nodes licence which give better insights into cycling patterns. Nevertheless currently the city of Johannesburg does not possess any information on cycling patterns, hence the Strava Metro would be a good start into providing such information. Accordingly, we acquired the Origination and Destination licence that records the start and end of cycling polygon activities. Data received from Strava was in $\mathrm{dbf}$ and shapefile format. The dbf contained all the cycling attributes whilst the shapefile contained the location (suburbs) of where the cycling activities took place in Johannesburg. Accordingly the two where joined using the join function in ArcGIS so as to spatially analyse the data. The data was then projected to Transverse Mercator projection. 
The data was analysed and visualised in ArcGIS 10.3 software. Cycling patterns where analysed on the basis of the type (whether recreational or commuting), time, frequency as well as the origin and destination. The analysis was at city and neighbourhood level. At neighbourhood level the Spatial statistics, spatial analysist and map algebra functions of ArcGIS were utilised to calculate the cycling trips, the originating and destination polygons as well as the intersected polygons.

\section{RESULTS AND DISCUSSION}

The number of cycling trips recorded by Strava Metro for Johannesburg was 84297 for year 2014. Only 20\% of the cycling trips are for commuting whereas recreational trips accounts for approximately $80 \%$ of the cycling trips in the city of Johannesburg. The number of trips recorded in a month is presented the graph in figure 2 below.

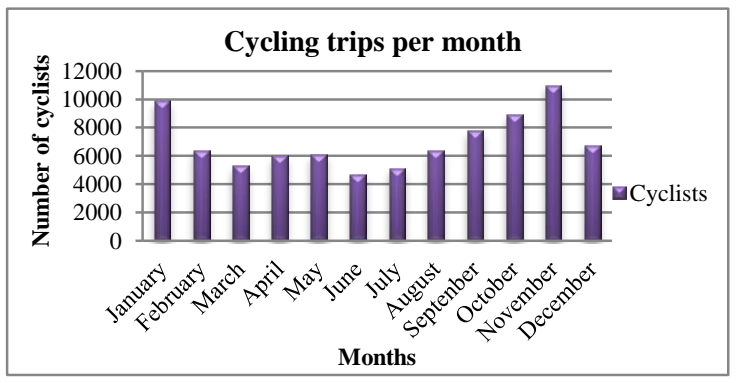

Figure 2: Cycling trips per month for year 2014

According to the graph on figure 2 above, November has the most cycling trips (with 10997 trips) the second highest is January with 9880 trips. The lowest is June with 4660 , followed by July with 5151 . There are higher numbers of cycling trips were recorded at the beginning of the year and towards the end of the year. During the middle of the year in, June and July, the number of cycling trips decreases significantly.

This could be because it is summer during the beginning of the year and also towards the end of the year and it is winter during the middle of the year. This confirms that cycling is affected by physical aspects such as weather, and climate, which provides reasons why it could be a seasonal activity. Johannesburg can get very cold during the winter season with temperature plummeting to -5 degrees and the months just before and after the winter season can also experience lower temperatures. The cold climate might make it difficult to cycle during the middle of the year.

According to the data provided by Strava, there are preferable hours for cycling in a day. Figure 3 below shows cycling trips per hour of the each day for the year in 2014.

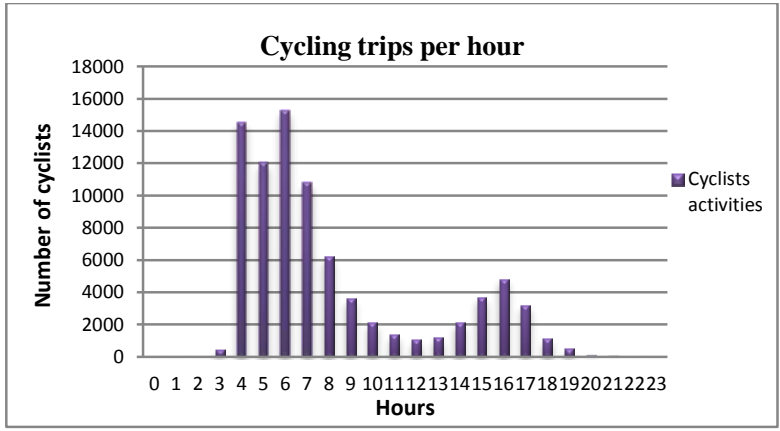

Figure 3: All cycling trips per hour

There is a higher number of cycling trips in the morning, the number decreases as it approaches midday, and starts increasing after midday, during the afternoon and declines again in the evening after 16:00 until midnight. The highest number of cycling trips was recorded at 06:00 and at 04:00 and the lowest numbers of trips were recorded from 20:00 to 03:00. Most of the people who leave for work and school leave their origin (which is usually their place of residence) early in the morning. This explains the higher number of cycling trips in the morning between 04:00 and 07:00 as compared to the rest of the day.

Similarly, most recreational cyclists prefer cycling in the morning before they start with their daily activities and in the afternoon. Most of the recreational cyclists use cycling as a means for daily exercising, therefore it is preferably done in the morning and afternoon at their spare time. During the day, people are at work or at school and therefore the number decreases as most people will be busy with other activities.

The number of trip origin in a polygon and the number of trip destinations in a polygon are illustrated in figure below. Figure 4 (a) below shows cycling trip origins whereas Figure 4 (b) denotes the number of trip destinations.

From the maps in figure 4, Kibler Park in the south east and Hyde Park in the north have trip origins and destinations that are above 7500 . Other suburb with a high cycling activity (O-D >4500) include; Parkview, Carlswald, Kleve Hill Park, Morningside, Hurlingham and Waterval Estate. Suburbs with median cycling actives include Highlands North, Houghton Estate and Willowbrook. Linden has trips origins that are above 3000 and have destinations that are more than 1500 but less than 3000. Ferndale and Windsor has trips origins that are above 1500 and have destinations that are less than 1500 . Bergbron and Randparkrif has trips origins and destinations that are above 1500 . The rest of the polygons have trip origins and destination that are less than 1500 . 


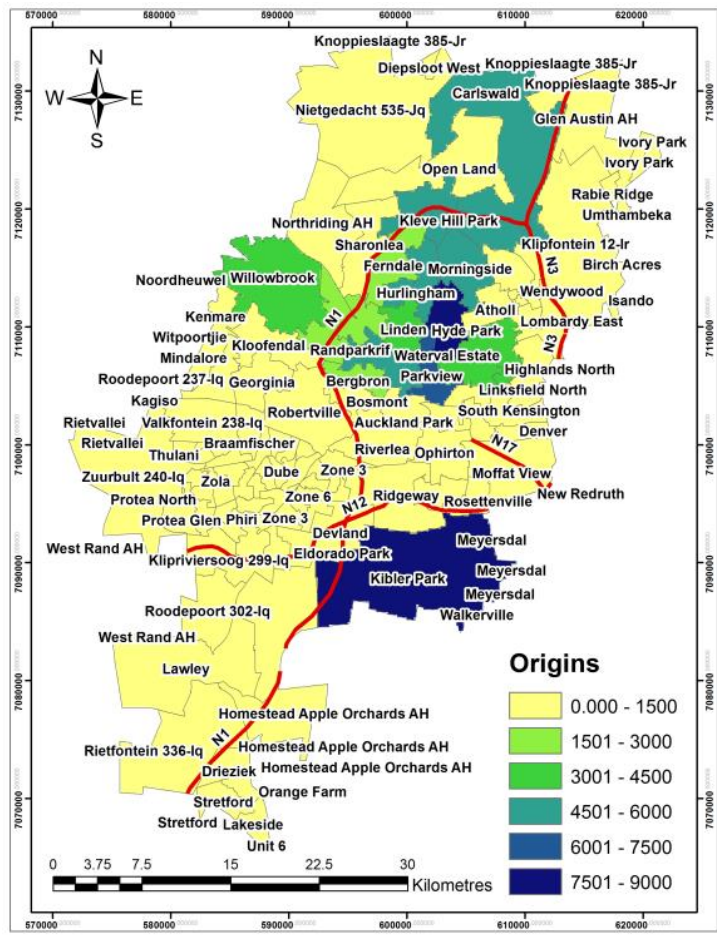

(a)

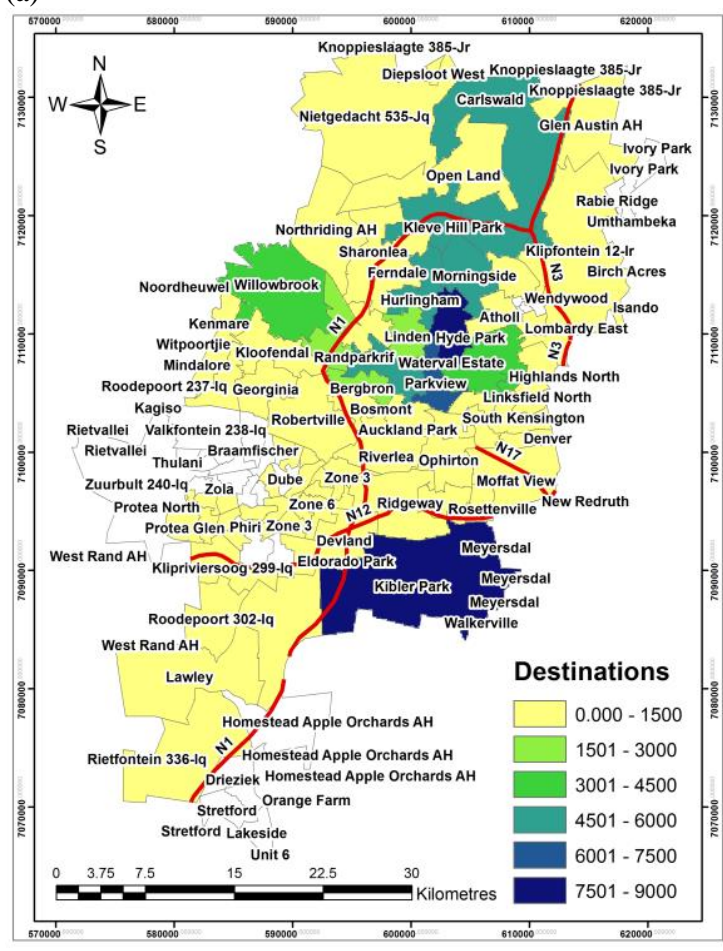

(b)

Figure 4 (a) (b): O-D polygons for cycling trips

Cycling is a short distance means of transport and therefore considering the sizes of the Strava data polygons, some cycling trips started and ended within the same polygon. The maps above also indicate that most polygons have higher number of trips origins than the number of trip destinations. It is also indicated that except Kibler Park at the south eastern part Johannesburg, most of the suburbs with higher cycling O-D's are from the centre of the city towards the north of the city and some on the east.
Most of the suburbs are along the N1 (National Road 1) and the M3 (Municipal road 3) routes. The suburbs are from Houghton Estate, Parkveiw, Waterval Estate at the centre and as one move north there are Hyde Park, Linden, Hurlingham, Morningside, and Kleve Hill Park and at the north of the city there is Carlswald. Suburbs at the centre are Bergbron, Randparkrif, Windsor and Willowbrook. Most of these suburbs are concentrated by high income households. Some are situated closer to Sandton which recently has a higher economic value even as compare to the CBD.

According to an income distribution map provided in the Integrated Development Plan (IDP), it indicated that lowincome earners mostly concentrate the south of the city of Johannesburg. These places with high population densities and low income rates are places such as Soweto and Orange farm, the CBD and Ivory Park. From these results one can assume that the level of income is directly proportional to the number of cycling activities. It might not directly influence the cycling activities but, it is related to property values and resource availability.

The collection of this data requires the use of a smartphone and for a person to have a certain level of technological or telecommunication knowledge. Low incomes are known to have a higher level of illiteracy. Most of the low income households might not afford the smartphone and therefore cannot contribute any means of crowdsourcing. The use of Strava Metro is not yet well known especially to such communities in Johannesburg which are mostly the southern and the south western part of the city. This is where most of the townships and the informal settlements are located. This is where the use of the non-motorised transportation is mostly not safe. The high levels of nonmotorised risks are predicted at these areas. Cycling at the poor townships in Johannesburg raises a lot of safety issues and this might also explain the limited number of cycling activities in the low income townships in the south.

Although some of the people who use cycling as a means of commuting transport use this means of transport by choice there are some of the people who use this mode of transport because they are stranded and cannot afford any other means of transport besides walking and cycling. This would also explain the less percentages of commuting trips recorded by this mobile application. Most of the recreational cyclists use cycling as a means of exercising to keep their bodies fit, and it is preferable for the cyclist to exercise in the morning and afternoon at their spare time. This explains the high numbers in the morning hours and the afternoon. During the day, people are at work or at school and therefor the number decreases.

The number of cycling activities in a polygon could be affected by the number of gated communities that are in a specific polygon. The results of the data collected indicated that most of the cycling trips are spread towards the north of Johannesburg. These are the areas where there are the most gated communities in the city of Johannesburg. Gated communities have an impact on cycling in such a manner that, they are safer and cycling activities are provided for in most of them. Most of these gated communities are closer to people's work places, shopping centres and schools, therefore, it easier to use NMT in these areas. Most of the households in these gated 
communities and even in most parts of the region are high income households in Johannesburg.

\section{IMPLICATION TO POLICY}

The study has several implications for policy. The world is moving towards the use of intercommunication technology (ICT) and governments have to keep up with the development of technology. These implications include, providing an easier way for data collection and therefore, the decision making process and providing an up to date insights of the cycling trips in the city of Johannesburg.

Traditional ways of data collection are popular in South African researches. However this study demonstrates the utility of Strava to collect data at a consistent spatial extent and for a continuous period thereby monitoring cycling activities. Crowd-sourced data is also frequently selfupdating, whereas it is not easy to frequently update data using the traditional way of data collection such as traffic counts which are often cumbersome, expensive and unreliable.

The frameworks (non-motorised framework and nonmotorised transport policy) for non-motorised transport in Johannesburg does not use the collection of the actual number of people using non-motorised transportation as a strategy for the provision of infrastructure, but use criteria such as proximity to prioritise areas. It is assumed that the people use the NMT for only short distance. These policies then prioritise the areas closer and within the city centre because residential areas are in closer proximity to services. To a certain extent, using the criteria does work, but sometimes the infrastructure is provided without the knowledge of the number of people who needs such infrastructure. Some of the areas that need cycling infrastructure more are often the last on the priority list.

Most people who live in such areas do not use cycling. This neglects the fact that the poor mostly stays in areas far from services and therefor the stranded have to cycle for long distances because they cannot afford public transport. These areas should be the first on the priority list since according to Spatial Planning and Land Use Management Act (16 of 2013) the poor are to be prioritised when it comes to such infrastructure provisions. Such knowledge to the stakeholders will help in more informed frameworks and policies and the priority list will be restructured.

Information from Strava can therefore assist municipalities in planning for infrastructure as it shows the cycling trends, patterns and behaviour. For example the current cycling lanes built in the Johannesburg where built without evidence based research as hardly any cyclists utilise these lanes. Perhaps the City of Johannesburg can follow cities such as in Portland Oregon who have used data from Strava to plan for NMT infrastructure. From a community perspective Strava can also assist planners and the residents to know where most of the cyclists are and safe routes to take when cycling, particularly in South Africa with a high crime rate. Moreover data from Strava can perhaps make it possible Johannesburg to achieve smart city status.
There are still things that need to be done for the city of Johannesburg to achieve its goals. This involves more promotion of the use of NMT. This includes hosting more cycling activities, encouraging cyclists to contribute to crowdsourced data by using the Strava app to record any NMT trip. This will help provide adequate infrastructure, where needed and will make cycling safe. That is when more people might decide to use NMT after all. It will also make it easier for the decision makers, policy makers, and most of the leaders to lead by example and stop being too attached to the cars.

\section{CONCLUSION}

To conclude, it is clear that crowd-sourced data (Strava Metro) can be a useful tool when it comes to decisionmaking and the formulation of policies. It can be an essential tool to plan for non-motorised transportation in Johannesburg and throughout the country. There is still a lot of work to be done before this application can be used to its maximum potential and before people move to NMT. With proper education, the right investment, maximum enforcements of traffic laws, crowd-sourced data a lot can be accomplished with regards to the efficient use of motorised transportation as well as provision for information that can be used in transportation planning in Johannesburg. 


\section{ACKOWLEDGEMENTS}

I would like to express my sincere gratitude to my supervisor Dr W Musakwa for the support, motivation, patience and knowledge, to my parents Mr and Mrs Selala for their support, encouragement and prayers.

\section{REFERENCES}

Angel, S., Sheppard, S., \& Cinco, D. (2005). The Dynamics of Global Urban Expansion, World Bank, Washington.

Anselin, L. (2012). From SpaceStat to Cyber GIS: Twenty Years of Spatial Data Analysis Software. International Regional Science Review. Vol 35 (2): 131-157

ASSR. 2008.

http://www.assr.nl/conferences/documents/Staffsempape rBourgouinnov.2008.pdf (accessed on 26/02/2014)

Banister, D. \& Hickman, R. (2006). How to design a more sustainable and fairer built environment: transport and communications. IEEE Proceedings of the Intelligent Transport System. Vol 153 (4): 276-291.

Beavon, K. (1998). "Nearer my Mall to Thee: The Decline of the Johannesburg Central Business District and the Emergence of the Neo-Apartheid City," Seminar Paper, University of the Witwatersrand, Institute for Advanced Social Research

Behrens, R. (2004). Understanding Travel Needs of the Poor: Towards Improved Travel Analysis Practices in South Africa. Transport Reviews: A Transnational Transdisciplinary Journal. Vol 24(3): 317-336

Blanco, H., Alberti, M., Forsyth, A., Krizek, K. J. Rodriguez, D. A., Talen, E. \& Ellis, C. (2009). Hot , congested, crowded and diverse: Emerging research agendas in planning. Progress in Planning. vol 71(4): 153205

Broach, J., Dill, J. \& Gliebe, J. (2012). "Where Do Cyclists Ride? A Route Choice Model Developed With Revealed Preference GPS Data." Transportation Research Part A: Policy \& Practice. Vol 46(10): 1730-1740.

City of Cape Town. (2003). MSDF Review - Phase 1: Spatial Analysis, Trends and Implications. Draft Report April/May 2003. Prepared for the Spatial Planning and Environment: Development Services Branch

City of Johannesburg. (2013). 2012/16 Integrated Development Plan (IDP).

Dewar, D. \& Todeschini, F. (2004). Rethinking Urban Transport after Modernism. Lessons from South Africa. Aldershot: Ashgate Publishing.

Filippi, F., Fusco, G. \& Nanni, U. (2013). User empowerment and advanced public transport solutions. Procedia - Social and Behavioral Sciences. Vol 87: 3-17.

Frank, L.D., Greenwald, M. J., Winkelman, S., Chapman, J. \& Kavage, S. (2010). Carbonless footprints : Promoting health and climate stabilization through active transportation. Preventive Medicine. Vol 50: S99-S105.

Freire, C. E. A. \& Paincho, M. (2014). Development of a Mobile Mapping Solution for Spatial Data Collection using Open-Source Technologies. Procedia Technology. Vol 16: 481-490

Gilroy, N. (2014). An Analysis of Cycling Infrastructure and Cycling Activity. Digital commons at Selom State University.

Gwala, S. (2007). Urban Non-motorised transport (NMT): A critical look at the development of urban NMT policy and planning mechanisms in South Africa from 19962006. Proceedings of the 26th Southern African Transport Conference (SATC 2007). Pretoria, South Africa. (9-12 July 2007)

Handy, S. \& McCann, B. (2010). "The Regional Response to Federal Funding for Bicycle and Pedestrian Projects: An Exploratory Study." Journal of the American Planning Association, Winter 2001. Vol 77(1): 23-38.

Hussein, W. \& Hussein, A. (2015). A sustainable planning approach to resolving transportation hub problems in Egyptian cities "proposed measurement matrix ". Transport and Traffic Sector Problems in Egypt. Vol 4(1): $1-16$.

Jennings, G. (2014). Finding our balance : Considering the opportunities for public bicycle systems in Cape Town, South Africa. Research in Transportation Business \& Management. 1-9

Johannesburg Roads Agency. (2000). Annual Report 2000-2001. From www.jra.org.za/. (accessed 04 February 2015)

Jou, K.K. (2011). Pedestrian Areas and Sustainable Development. World academy of science, engineering and technology. Vol 5(5): 423-430.

Kenworthy J. \& Hu, G. (2002). Transport and urban Form in Chinese Cities: An International Comparative and Policy Perspective with Implications for Sustainable Urban Transport in China. DISP. Vol 151 (4): 4-14.

Kenworthy, J.R. (2003). Transport energy use and greenhouse gases in urban passenger transport systems: A study of 84 global cities. In: International Sustainability Conference, 17 - 19 September, Fremantle, Western Australia

Lamondia, J.J. \& Moore, N. (2014). Comparing Bicycle Level of Service Measures, Roadway Characteristics, and Perceived Bike Route Suitability. 94th Annual Meeting of the Transportation Research Board. November 14, 2014

MacMichael, S. (2014). Strava moves into 'big data' London \& Glasgow already signed up to find out where cyclists ride. http://road.cc/content/news/118098stravamovesbigdatalo ndonglasgowalreadysignedfindoutwherecyclistsride (accessed 04 February 2015) 
Mammon, N., Ewing, K. \& Peterson, J. (2008). Urban Challenges of Inclusive Cities - towards a spatial realm for all. Urban development component of a second economy strategy for the office of the presidency - spatial planning (draft). 24 April 2008

Marquet, O. \& Miralles-Guasch, C. (2015). The Walkable city and the importance of the proximity environments for Barcelona's everyday mobility. Cities. Vol 42: 258-266

Mbara, T.C. \& Celliers, C. (2013). 'Travel patterns and challenges experienced by University of Johannesburg off-campus students'. Journal of Transport and Supply Chain Management. Vol 7(1):1-8.

Mohan, D. (2002). Traffic safety and health in Indian cities. Journal of Transport and Infrastructure. Vol 9(1): 79-92.

Muhammed, F. B., Yavuz, S. Y \& Murat, D. (2011). Crowdsourcing Location-based Queries. Second IEEE Workshop on Pervasive Collaboration and Social Networking. Department of Computer Science and Engineering. University at Buffalo

Municipal Demarcation Board. (2013). Annual Report 2012/2013.www.dermacation.org.za (accessed on 17 March 2014)

Navarro, K. F., Gay, V., Golliard, L., Johnston, B., Leijdekkers, P., Vaughan, E., Wang, X \& Williams M. (2013). Social Cycle: What can a mobile app do to encourage cycling? Proceedings - Conference on Local Computer Networks, LCN, Faculty of Engineering and IT UTS, University of Technology, Sydney, Australia. pp2430.

Neutens, T., Delafonteine, M., Scott, D. M. \& De Maeyer, P. (2012). A GIS-based method to identify spatiotemporal gaps in public service delivery. Applied Geography. Vol 32(2): 253-264.

Newman, P. \& Kenworthy, J. (1996). 'The land usetransport connection: an overview'. Land Use Policy. Vol 13(1):1-22.

Smith, W. (2014). Mobile interactive fitness technologies and the recreational experience of bicycling: a phenomenological exploration of the Strava community. All theses paper, 1952.

StravaMetro. (2014). StravaMetro Product Documentation for Melbourne AUS Sample.

StravaMetro. (2014). StravaMetro User Guide and Manual.

Struwig, C. B., Andersen, S. J. (2013). Challenges in providing Integrated Traveler Information in a Developing Country Environment. Proceedings of the 16th International IEEE Annual Conference on Intelligent Transportation Systems (ITSC 2013), Stellenbosch University, South Africa. (October 6-9, 2013).

Todes, A. (2012). New Directions in Spatial Planning? Linking Strategic Spatial Planning and Infrastructure
Development. Journal of Planning Education and Research. Vol 32: 400-414

Todes, A., (2009). Chapter 8: Planning, Spatial Structure of Cities and Provision of Infrastructure. Global Report on Human Settlements 2009: Revisiting Urban Planning, revised paper.

Visser, D., Steynberg, M., van Biljon, B. \& Scheepers, J. (2013). Gautrans guidelines for the provision of Pedestrian and bicycle facilities on provincial Roads in Gauteng. Proceedings of the 22nd Southern African Transport Conference (SATC2003). Pretoria, South Africa. 14 - 16th July 2003.

Waterson, B. J., Rajbhandari, B. \& Hounsell, N. B. (2003). Simulating the impacts of strong bus priority measures. Journal of Transportation Engineering-ASCE. Vol 129: 642-647.

Yazid, M. R. M., Ismail, R. \& Atiq, R. (2011). The Use of Non-Motorized For Sustainable Transportation in Malaysia. Procedia Engineering. Vol 20:125-134. 